\title{
Preparación del patrimonio cultural de la Tierra para el riesgo de un conflicto armado: documentación y registro para su protección
}

Ana Laia Lázaro Feo ${ }^{a}$

${ }^{a}$ Doctora en Derecho Internacional por la Universidad de Valencia. ana_laia@hotmail.com

\begin{abstract}
Resumen
El patrimonio arquitectónico y los bienes culturales en general se ven afectados por diferentes amenazas. Una de las más recurrentes en el tiempo son los conflictos armados. En concreto, la labor previa al estallido de una guerra es clave para su protección durante la misma, y, más particularmente, la documentación y el registro de los bienes culturales pueden contribuir en gran medida a su protección. Desde esta perspectiva, la comunicación tiene como objetivo analizar cómo los instrumentos internacionales más relevantes del ámbito abordan esta situación a través de la adopción de medidas preventivas. Se hará referencia al articulado específico de algunos de ellos que incluyen la importancia de la documentación y del registro del patrimonio cultural en la labor de preparación para el riesgo. Además, el problema que se ha dado en los últimos tiempos es que en algunos lugares se han destruido también los inventarios de los museos, haciendo casi imposible la recuperación de determinadas piezas. Para evitar, por tanto, que la información sobre los bienes culturales se pierda, se propone la idea de creación de un sistema digitalizado mundial interconectado de clasificación y fichado entre los distintos países sobre su patrimonio cultural susceptible de ser protegido.
\end{abstract}

Palabras clave: patrimonio cultural, conflicto armado, derecho internacional, prevención, documentación, registro.

\begin{abstract}
Architectural heritage and cultural property are usually affected by a number of threats. One of the most recurring problems is armed conflict. In fact, previous work to the outbreak of war is key to its protection, and more specifically the documentation and registration of cultural property may go a long way towards boosting its protection. From this standpoint, this communication aims to analyse how the most important international instruments in the field address this situation through the adoption of preventive measures. Reference will be made to the specific articles contained in some of them referring to the importance of documenting and recording the local cultural heritage when facing a high-risk situation. To make things worse, over the last few years many inventories of museums have been destroyed, complicating further the possibility of recovering some of those cultural objects. In order to prevent information on cultural heritage from being lost, a proposal is presented on the idea of creating an interconnected global digitized system of classification and registration of cultural heritage shared among countries.
\end{abstract}

Keywords: cultural heritage, armed conflict, international law, prevention, documentation, register. 


\section{Introducción}

La protección del patrimonio cultural en el ámbito internacional es una necesidad que, como se ha visto en los últimos años, es necesario revisar. Los conflictos armados son una de las amenazas más devastadoras para los bienes culturales en la actualidad. En la mente tenemos las imágenes de la destrucción del patrimonio cultural de Siria durante el conflicto armado iniciado en marzo de 2011. Numerosos sitios de gran importancia cultural han sido destruidos a consecuencia de la guerra como la Gran Mezquita de Alepo, el museo nacional de la ciudad, el teatro romano de Bosra y Palmira entre otros (UNITAR/UNOSAT, 2014). Todas estas destrucciones han sido ocasionadas por los ataques producidos entre las partes durante el conflicto, aunque el Derecho internacional protege los bienes civiles y el patrimonio cultural en este tipo de situaciones bélicas. De poco han servido las Resoluciones del Consejo de Seguridad de las Naciones Unidas que han hecho referencia al patrimonio cultural sirio como la Resolución 2139 de 2014 que:

"Exhorta a todas las partes a que pongan de inmediato fin a toda la violencia que ha provocado sufrimientos humanos en la República Árabe Siria, preserven el rico mosaico de la sociedad y el patrimonio cultural de Siria, y tomen las medidas adecuadas para asegurar la protección de los lugares del país considerados patrimonio mundial." (Consejo de Seguridad de las Naciones Unidas, 2014, p. 2).

La Resolución 2199 de 2015, donde se incluye un apartado sobre el patrimonio cultural condenando la destrucción del patrimonio cultural en Iraq y en Siria por grupos terroristas armados (Consejo de Seguridad de las Naciones Unidas, 2015). O la Resolución 2347 de 2017 (Consejo de Seguridad de las Naciones Unidas, 2017), que es considerada como histórica, por la Organización de las Naciones Unidas para la Educación, la Ciencia y la Cultura (UNESCO, 2017), por ser la primera que se centra en exclusiva en la protección del patrimonio cultural.

La pérdida patrimonial en el ámbito cultural de un país no afecta únicamente a este, sino que es un menoscabo para la población mundial en general. Por ello, la importancia de la protección internacional debe asumirse como un deber general para todos los pueblos y naciones. Iniciado un conflicto armado, la tarea de salvaguardar el patrimonio es muy complicada, y, por ello, las medidas preventivas tomadas con anterioridad al inicio del mismo son básicas para que la protección pueda llegar a ser eficaz una vez la guerra haya comenzado. Una de estas medidas preventivas, que puede ayudar a proteger el patrimonio durante los conflictos armados, es la documentación y el registro de los bienes culturales llevados a cabo en tiempos de paz. La normativa internacional específica de protección de patrimonio cultural durante las guerras incluye en alguno de sus tratados, como ahora veremos, este tipo de medidas preventivas tan necesarias.

\section{La protección del patrimonio cultural durante las guerras en el Derecho internacional}

Existe un sistema de protección internacional nutrido de diferentes instrumentos jurídicos internacionales que preservan el patrimonio cultural en este tipo de escenarios bélicos. Para las situaciones definidas como conflicto armado se aplica una rama del Derecho internacional público, que es el Derecho internacional humanitario.

Dentro de este Derecho internacional humanitario el instrumento más importante en el ámbito de la protección del patrimonio cultural es la Convención para la protección de los bienes culturales en caso de conflicto armado de 1954 . Fue el primer tratado multilateral internacional con vocación universal que se centró exclusivamente en la protección del patrimonio cultural para situaciones de conflicto armado. Y aunque esté destinada a ser aplicada exclusivamente en conflicto armado, la Convención debe aplicarse también en tiempos de paz, tanto en la esfera interna de cada Estado Parte, como en el plano internacional, ya que, como dice su preámbulo, "esta protección no puede ser eficaz a menos que se organice en tiempo de paz" (Convención para la protección de los bienes culturales en caso de conflicto armado, 1954).

En ella encontramos dos deberes esenciales, el de respeto y el de salvaguardia de los bienes culturales. Este segundo deber, el de salvaguardia, es el que debe aplicarse fundamentalmente en tiempos de paz. Sin embargo, la propia Convención deja a los Estados Parte la libertad de elegir las medidas que consideren oportunas para ello. Lo hace sin exigir unos mínimos, lo que debilita la protección. Específicamente, en su artículo 3 sobre salvaguardia de los bienes culturales, establece que: "Las Altas Partes Contratantes se comprometen a preparar en tiempo de paz, la salvaguardia 
de los bienes culturales situados en su propio territorio contra los efectos previsibles de un conflicto armado, adoptando las medidas que consideren apropiadas" (Convención para la protección de los bienes culturales en caso de conflicto armado, 1954). Como vemos, no hace hincapié en ellas, ni las detalla, ni sugiere unos mínimos en concreto a desarrollar por el Estado, dando por válidas las que "consideren apropiadas".

Existe un Segundo Protocolo a la Convención, de fecha de 1999, donde sí se especifican algunas de las acciones a llevar a cabo dentro de este deber de salvaguardia, aunque no todos los Estados Parte de la Convención de 1954 lo son de este Segundo Protocolo. 133 Estados son Parte de la Convención de 1954 y únicamente 83 del Segundo Protocolo.

Este Protocolo amplía y desarrolla la Convención, y una de las medidas incluidas en él es la confección de inventarios. Disposición fundamental en la tarea de la preparación para evitar el riesgo del patrimonio cultural. Dentro del Capítulo 2, sobre disposiciones generales relativas a la protección, se incluye, en su artículo 5 concerniente a la salvaguardia de los bienes culturales, que: "Las medidas preparatorias adoptadas en tiempo de paz para salvaguardar los bienes culturales contra los efectos previsibles de un conflicto armado conforme al Artículo 3 de la Convención, comprenderán, en su caso, la preparación de inventarios" (Segundo Protocolo de la Convención de La Haya de 1954 para la Protección de los bienes culturales en caso de conflicto armado, 1999).

Además de mencionar otras iniciativas como la planificación de medidas de emergencia para la protección contra incendios o el derrumbamiento de estructuras, y el suministro de una protección adecuada in situ de los bienes. Aquí observamos que, en este Segundo Protocolo de 1999, ya sí se hace referencia explícita a la preparación de inventarios para paliar los efectos de una guerra sobre los bienes culturales.

Hay que añadir que los daños y la destrucción no son los únicos problemas a los que se enfrentan los bienes culturales en las guerras, además hay que sumar la exportación ilícita de los mismos. Para frenar este tráfico ilícito de patrimonio cultural existe un acuerdo internacional específico de 1970, que es la Convención sobre las medidas que deben adoptarse para prohibir e impedir la importación, la exportación y la transferencia de propiedad ilícitas de bienes culturales. Esta Convención considera que, para ser eficaz, la protección del patrimonio cultural debe organizarse tanto en el plano nacional como en el internacional, lo que exige una estrecha colaboración entre los Estados. El artículo 5 de la misma señala que los Estados Partes deben establecer en su territorio servicios de protección del patrimonio cultural que garanticen las funciones que detalla la misma. Y en el apartado b) de este artículo 5 especifica la función de: “b) establecer y mantener al día, a partir de un inventario nacional de protección, la lista de los bienes culturales importantes, públicos y privados, cuya exportación constituiría un empobrecimiento considerable del patrimonio cultural nacional" (Convención sobre las medidas que deben adoptarse para prohibir e impedir la importación, la exportación y la transferencia de propiedad ilícitas de bienes culturales, 1970).

De esta forma, se acredita que los instrumentos internacionales más importantes para frenar los efectos negativos de las guerras sobre los bienes culturales y para evitar el tráfico ilícito de los mismos, definen un marco legal mínimo que debería garantizar la protección de los bienes culturales en situaciones de conflicto armado. Así, tanto la Convención de 1954 incluyendo las medidas preventivas en general, y su Segundo Protocolo de 1999, además de la Convención de 1970 especificando el deber de crear inventarios nacionales de patrimonio cultural para paliar los efectos negativos sobre el mismo, incorporan en su articulado, de una forma u otra, la conveniencia de tomar este tipo de medidas de salvaguardia en tiempos de paz.

\section{La importancia de la documentación y el registro del patrimonio cultural para la prevención de los daños}

Solo con un ejemplo nos podemos hacer la idea de la importancia de la documentación y el registro del patrimonio cultural en su preparación para el riesgo de un conflicto armado. En 2003, con la intervención militar de la Coalición internacional liderada por Estados Unidos en Iraq, vimos cómo el patrimonio cultural no era una de las prioridades en la protección de las unidades militares, asignándose los recursos a la protección de otro tipo de estructuras como los oleoductos. El Museo Nacional de Bagdad resultó gravemente dañado y saqueado en los primeros días de la ocupación (Lázaro, 2019). Las tropas estadounidenses entraron en Bagdad el 9 de abril de 2003, pero hasta el día 16 no se situaron 
en el Museo Nacional de Iraq para su protección. El Museo fue saqueado del jueves 10 de abril al sábado 12. Después de meses de trabajo se estableció en 15.000 los objetos desaparecidos del Museo; entre ellos monedas, esculturas, cerámicas, objetos de metal, fragmentos arquitectónicos, tablas cuneiformes y la mayor parte de la colección del Museo de los valiosos sellos cilíndricos de la época sumeria (George, 2008).

Por este motivo, las medidas de salvaguardia tomadas con anterioridad a las guerras son básicas para la protección de los bienes culturales y para la recuperación de las piezas desaparecidas. Pues la afectación de este tipo de bienes durante las guerras es algo que, desgraciadamente, se repite en cada una de ellas, y su protección real y eficaz durante los combates es, en numerosas ocasiones, impracticable.

Mencionar, además, que la Convención sobre la protección del patrimonio mundial cultural y natural de 1972, que está pensada para proteger el patrimonio en tiempos de paz, y no específicamente durante los conflictos armados, y no es parte del Derecho internacional humanitario, también establece unas Listas que gozan de gran reconocimiento y publicidad, las Listas del patrimonio Mundial, pero que, en mi opinión, no son suficientes para catalogar el patrimonio cultural de los Estados. Tal y como la propia Convención establece en su artículo 12:

"El hecho de que un patrimonio cultural y natural no se haya inscrito en una u otra de las dos listas de que tratan los párrafos 2 y 4 del artículo 11 no significará en modo alguno que no tenga un valor universal excepcional para fines distintos de los que resultan de la inscripción en estas listas.” (Convención sobre la protección del patrimonio mundial cultural y natural, 1972).

Ese mismo reconocimiento por parte de la UNESCO de su alcance limitado, justifica que sigue siendo primordial el trabajo de inventariado exhaustivo de los bienes culturales de los Estados para su protección.

\section{Nuevos retos para la protección}

Además, el problema que se ha dado en los últimos tiempos es que, conjuntamente a los daños de los bienes culturales, su robo y posterior exportación ilegal durante los conflictos armados, en algunos lugares se han destruido también los inventarios de los museos, haciendo casi imposible la recuperación de alguna de las piezas al haber desaparecido la información sobre las mismas. En algunas ocasiones, la desaparición ha sido de manera colateral por los fuegos durante los combates, pero, en otras, ha sido de forma intencionada para que no exista constancia de las piezas de una colección.

En muchas partes del mundo si desaparecen estos registros locales o nacionales es muy posible que no haya forma de restablecerlos de manera idéntica. Y la localización de las piezas y el análisis de los daños de las mismas sean impracticables. Para evitar este tipo de problemas y que la información sobre los bienes culturales se pierda, me gustaría terminar añadiendo la idea, desarrollada en mi tesis doctoral, de creación de un sistema mundial digitalizado interconectado de clasificación e inventariado entre los distintos países sobre su patrimonio cultural susceptible de ser protegido.

Se trataría de elaborar un registro central digitalizado gestionado por un organismo internacional, como por ejemplo la UNESCO, al que los diferentes responsables estatales, como los ministerios de cultura o las direcciones generales de antigüedades de cada país, mandaran las fichas con la información de cada uno de sus museos con las piezas de las que constan las colecciones, además de registrar los yacimientos arqueológicos y otros bienes culturales inmuebles en este registro.

Sería una labor que tendría que empezar en las bases culturales, llevada a cabo por historiadores, arqueólogos y trabajadores de los museos y bibliotecas para identificar los lugares y las colecciones existentes en el territorio del país. Más tarde pasarían estas listas a sus responsables superiores de los ministerios o direcciones generales, y, por último, estos deberán transmitir la información a la organización internacional encargada de la gestión, para que se incorporen los datos en el registro único que se constituyera para esta finalidad. 


\section{Conclusiones}

Como acabamos de comprobar, la documentación y el registro se incluyen en los instrumentos jurídicos internacionales más importantes del ámbito de la protección de los bienes culturales durante un conflicto armado como medida preventiva básica para que la labor de salvaguardia sea llevada a cabo de manera eficaz iniciado un conflicto armado.

En lo que se refiere a España, nuestro país ha firmado los instrumentos jurídicos internacionales mencionados, y, como Parte en los mismos, debería poner en marcha inventarios nacionales de protección con la lista de los bienes culturales importantes, públicos y privados, susceptibles de ser protegidos. Ya en el año 1900 por Real Decreto, a propuesta del Ministro de Instrucción pública y Bellas Artes, se establecía la creación de un Catálogo monumental y artístico de la Nación, pero que nunca llegó a terminarse (Ministerio de Educación, Cultura y Deporte, 2012). Hoy, lo más parecido a ello que podemos encontrar en España es el Registro General de Bienes de Interés Cultural o el Inventario General de Bienes Muebles.

La creación de un registro central digitalizado, gestionado por un organismo internacional como el que se propone en la comunicación, sería factible a día de hoy con la voluntad de los Estados y las organizaciones internacionales dedicadas a la protección del patrimonio cultural. Las nuevas tecnologías, en la actualidad, nos dan la oportunidad de conectar la cultura de todos los puntos del globo. Sería perfectamente posible la organización de un registro único de este tipo alimentado por los Estados - que ayudaría a solucionar la pérdida de los archivos y catálogos en los casos de un conflicto armado. Facilitaría la salvaguardia del patrimonio cultural y evitaría que se repitieran los abundantes casos que han existido de mermas en el patrimonio cultural de los Estados y siguen existiendo, desgraciadamente, a día de hoy. Así, este Registro favorecería la protección del patrimonio cultural de manera eficaz durante las guerras.

\section{Referencias}

Consejo de Seguridad de las Naciones Unidas. (2014). Resolución 2139. S/RES/2139 (2014). Recuperado de http://www.un.org/es/comun/docs/?symbol=S/RES/2139(2014).

Consejo de Seguridad de las Naciones Unidas. (2015). Resolución 2199. S/RES/2199 (2015). Recuperado de http://www.un.org/en/ga/search/view_doc.asp?symbol=S/RES/2199\%20\%282015\%29.

Consejo de Seguridad de las Naciones Unidas. (2017). Resolución 2347. S/RES/2347 (2017). Recuperado de http://undocs.org/es/S/RES/2347(2017).

Convención para la protección de los bienes culturales en caso de conflicto armado hecha en La Haya el 14 de marzo de 1954. Boletín Oficial del Estado, núm. 282, de 24 de noviembre de 1960, 16189-16194.

Convención sobre la protección del patrimonio mundial cultural y natural, hecha en París el 23 de noviembre de 1972. Boletín Oficial del Estado, núm. 156, de 1 de julio de 1982, 17883-17887.

Convención sobre las medidas que deben adoptarse para prohibir e impedir la importación, la exportación y la transferencia de propiedad ilícitas de bienes culturales, hecha en París el 17 de noviembre de 1970. Boletín Oficial del Estado, núm. 31 , de 5 de febrero de 1986, 4869-4872.

George, D. (2008). The Looting of the Iraq National Museum. En P.G. Stone y J. Farchakh (Eds.), The Destruction of Cultural Heritage in Iraq (pp. 97-107). Woodbridge, Suffolk/Rochester NY: The Boydell Press.

Lázaro, A. L. (2019). La protección jurídica internacional del patrimonio cultural en los conflictos armados. Análisis comparado de los casos de Iraq (2003) y de Siria (2011). Tesis doctoral. Valencia: Universidad de Valencia.

Ministerio de Educación, Cultura y Deporte. (2012). El Catálogo Monumental de España (1900-1961). Investigación, restauración y difusión. Recuperado de https://es.calameo.com/read/000075335c05d3862c772.

Segundo Protocolo de la Convención de La Haya de 1954 para la Protección de los bienes culturales en caso de conflicto armado, hecho en La Haya el 26 de marzo de 1999. Boletín Oficial del Estado, núm. 77, de 30 de marzo de 2004, 13410-13417.

UNESCO. (2017). El Consejo de Seguridad de la ONU adopta una resolución histórica para la protección del patrimonio cultural. 24 de marzo de 2017. Recuperado de https://es.unesco.org/news/consejo-seguridad-onu-adopta-resolucion-historica-protecciondel-patrimonio-cultural. 
Preparación del patrimonio cultural de la Tierra para el riesgo de un conflicto armado: documentación y registro para su protección

UNITAR/UNOSAT. (2014). Satellite-based Damage Assessment to Cultural Heritage Sites in Syria. Recuperado de http://unosat.web.cern.ch/unosat/unitar/downloads/chs/FINAL_Syria_WHS.pdf 